\title{
Analysis of River Tributaries' Streamflow Contribution Using WEAP Model: A Case of the Ngwerere and Kanakatampa Tributaries to the Chongwe River in Zambia
}

\author{
Tewodros M. Tena ${ }^{1}$, Frank Mudenda ${ }^{2,3}$, Alick Nguvulu ${ }^{4}$, Phenny Mwaanga ${ }^{1}$, John M. Gathenya ${ }^{5}$ \\ ${ }^{1}$ Department of Environmental Engineering, The Copperbelt University, Kitwe, Zambia \\ ${ }^{2}$ Department of Civil Engineering, University of Pretoria, Pretoria, South Africa \\ ${ }^{3}$ Department of Civil and Environmental Engineering, The University of Zambia, Lusaka, Zambia \\ ${ }^{4}$ Geomatics Engineering Department, The Copperbelt University, Kitwe, Zambia \\ ${ }^{5}$ Department of Soil, Water and Environmental Engineering, Jomo Kenyatta University of Agriculture \& Technology, Nairobi, \\ Kenya \\ Email: tewodroslina@yahoo.com
}

How to cite this paper: Tena, T.M., Mudenda, F., Nguvulu, A., Mwaanga, P. and Gathenya, J.M. (2021) Analysis of River Tributaries' Streamflow Contribution Using WEAP Model: A Case of the Ngwerere and Kanakatampa Tributaries to the Chongwe River in Zambia. Journal of Water Resource and Protection, 13, 309-323.

https://doi.org/10.4236/jwarp.2021.134019

Received: March 8, 2021

Accepted: April 6, 2021

Published: April 9, 2021

Copyright $\odot 2021$ by author(s) and Scientific Research Publishing Inc. This work is licensed under the Creative Commons Attribution International License (CC BY 4.0)

http://creativecommons.org/licenses/by/4.0/

\begin{abstract}
Ngwerere and Kanakatampa Streams are the main tributaries of the Chongwe River. The Ngwerere stream originates from the city of Lusaka and meanders through Lusaka City and Chongwe Town for an approximate distance of 41 $\mathrm{km}$ before joining into the upper part of Chongwe River. The Kanakatampa Stream is a tributary of the Chongwe River. It meanders from the Kanakatampa Area for approximately $52 \mathrm{~km}$ before discharging into the middle of the upper part of the Chongwe River. The Chongwe River Catchment which is a sub-catchment of the Zambezi Basin drew the attention of researchers and policymakers when the Chongwe River started drying up in the dry seasons causing a water crisis particularly in the downstream regions of the middle catchment. Therefore, it is important from the water resources management perspective, to assess the contribution of tributaries into the flows of the Chongwe River. Ngwerere and Kanakatampa streams are socially, economically, and environmentally important streams for the city of Lusaka and surrounding area. This study, therefore, concentrated on evaluating the flow contribution of the two streams to the Chongwe River using the Water Evaluation And Planning (WEAP) tool. The streamflow data (1970-2010) recorded at the Chongwe Great East Road Bridge gauging station were used in the WEAP embedded Parameter ESTimation (PEST) auto-calibration tool to calibrate (1970-1999) and validate (2000-2010) the model. The monthly streamflow model calibration and validation results were assessed using the
\end{abstract}


correlation coefficient (CC), Coefficient of determination $\left(\mathrm{R}^{2}\right)$, Nash-Sutcliffe Coefficient of Efficiency (NSE), and Percent bias (PBIAS). The model performance results achieved were PBIAS of $1.24 \%, \mathrm{CC}=0.81, \mathrm{R}^{2}=0.66$ and NSE $=0.62$ during the calibration period and a positive PBIAS of $2.94 \%$, CC $=0.81, \mathrm{R}^{2}=0.67$ and NSE $=0.62$ during the validation period. The median of the flows $\left(\mathrm{Q}_{50}\right)$ was obtained from the historical flow duration curves (FDCs) generated in averaged intervals of 10-year from 1970 to 2019. The results showed that on average, the Ngwerere and Kanakatampa Streams contribute $52.8 \%$ and $29.6 \%$ respectively, to the flow of the Chongwe River in the upper and middle Catchment. The results also showed that the contribution of the Ngwerere and Kanakatampa Streams to the Chongwe River discharge has been reducing historically at a rate of $0.65 \%$ per decade and $1.35 \%$ per decade respectively over a period of 50 years (1970-2019). Suggestions for sustainable management of the tributaries such as the Ngwerere and Kanakatampa Streams were provided in this study.

\section{Keywords}

Ngwerere Stream, Kanakatampa Stream, Chongwe River, Zambezi Basin, WEAP Model, Water Resource Management, PEST

\section{Introduction}

Water is an essential resource that is necessary for life to exist. Freshwater is needed for farming, industrial, domestic, hydropower, recreational, and environmental activities [1]. Lack of access to freshwater is one of the main hindrances to health and socio-economic development in various communities. It is necessary to apply an integrated approach for the effective management of water resources, which considers the environmental, ecological processes, and human activities in the catchment. This explains the management of the multiple values of water and reflects the impacts of decisions across the environment, politics, science, tradition, engineering, economics, culture, and tradition. Water resources issues are widely discussed throughout the world. Addressing these issues requires information on the main factors that determine the hydrological changes and their related aspects of local water resources. Assessing water resources is a complex task and many factors need to be considered. Information on the spatial and temporal distribution of water resources is of vital significance to inform water management strategies and policies [2]. With the ever-increasing demand for water, there is a simultaneous growing need for a comprehensive understanding of the hydrology of river catchments [3] [4]. Tributaries often play a very vital role in the chemical properties, species diversity, productivity, and streamflow of rivers. The understanding of the tributaries' contribution to the river basins is vital for the management of water resources. The authors in [5] evaluated the contribution of tributaries in the Mekong river basin in South-East Asia and stated the significance of each tributary to the flows of the 
Mekong River including highlighting the factor of damming. The authors in [6] also analyzed the effect seven tributaries on the water quality of the Spring River in the United States of America (USA) and stated that the tributaries contributed $3.5 \%$ to $66.7 \%$ of the chemicals in Spring River. Bren [7] examined the contribution of the river Murray tributary to the flooding of the Barmar River Forest in Australia and stated that the removal of the Murray tributary would lead to a $55 \%$ decrease in the forest flooding. Others have reported the streamflow contributions of the tributaries of the Tigris river in Western Asia [8]. It is therefore clear that tributaries have a huge impact on the waterways of the river catchments.

In Zambia, river catchments serve as institutional entities that relate to the management of water resources in a specific area. Zambia has six main river catchments namely, Zambezi, Kafue, Luangwa, Chambeshi, Luapula, and Tanganyika (Figure 1), which are legally managed by the Water Resources Management Authority (WARMA) and the Department of Water Resources Development (DWRD) [9]. The Chongwe River Catchment which is a sub-catchment of the Zambezi River Catchment drew the attention of researchers and policymakers in the year 2012 when the Chongwe River started drying up in the dry seasons causing a water crisis especially in the downstream areas of the middle catchment. Various studies have been conducted by other researchers in this regard. Chisola \& Kuraz [10] investigated the patterns and implications of hydrologic regime change in the upper Chongwe River Catchment and reported that human activities in the upstream region of the catchment could be the major contributing factors to the changes in flow regime.

The authors in [11], modelled the hydrological water balance of Chongwe River Catchment using the Water Evaluation and Planning (WEAP) tool and

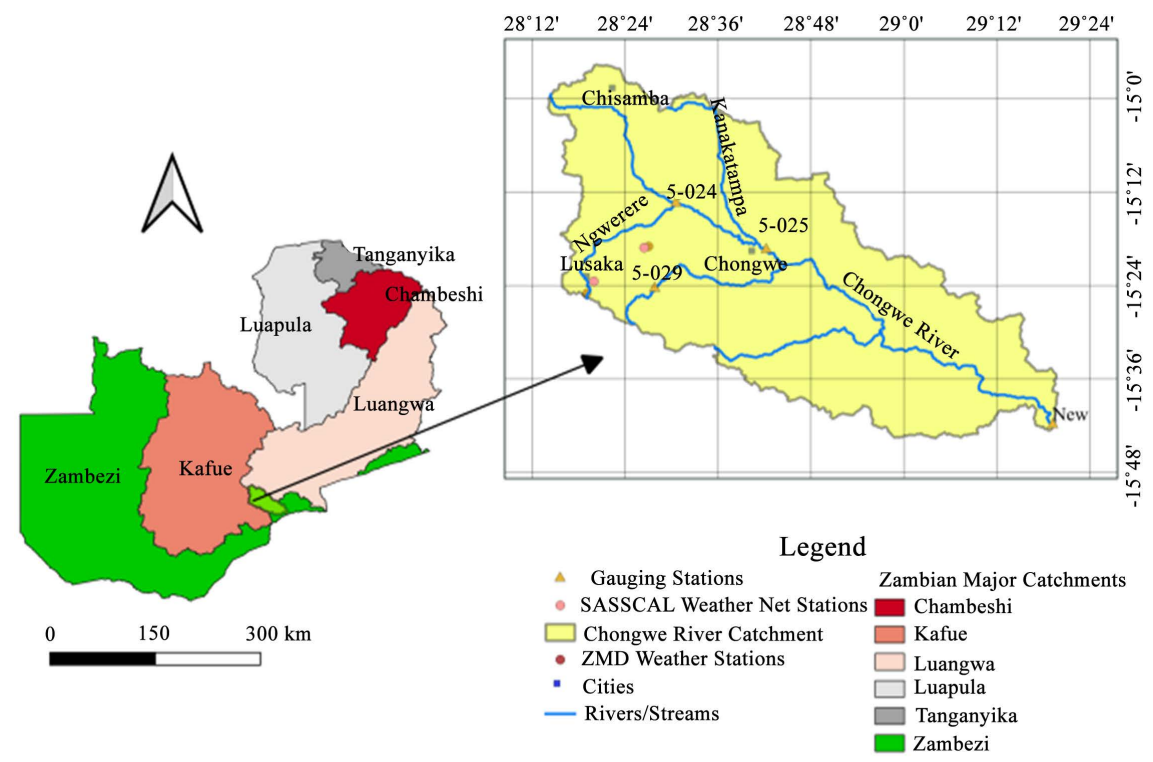

Figure 1. Location of Ngwerere and Kanakatampa Streams in the Chongwe river catchment (Modified after [11]). 
reported that the catchment received annual precipitation of $4603.12 \mathrm{Mm}^{3}$ (889 $\mathrm{mm})$, experienced an annual runoff of $322 \mathrm{Mm}^{3}(62.3 \mathrm{~mm})$, annual abstractions of $119.78 \mathrm{Mm}^{3}$ (23.3 mm), annual evapotranspiration (ET) of $4064 \mathrm{Mm}^{3}$ (796.3 $\mathrm{mm}$ ) and an external annual water transfer in the form of wastewater of 22.55 $\mathrm{Mm}^{3}$ (4.4 mm) via the Ngwerere stream. Tena, et al. [12] also investigated the impact of land use/land cover change (LULC) on the hydrological components in Chongwe River Catchment and reported that the pattern of LULC change between the years 1984 and 2017 affected the hydrology of the Chongwe River Catchment. Sedimentation due to soil erosion is also one of the most important problems in Chongwe River Catchment that directly affect the flow and performance of reservoirs to the reduction of water storage leading to reduced lifespan of small dams [13]. A study conducted by [13] on sedimentation and its effects on selected small dams in the east of Lusaka City indicated that the storage capacity of small dams is decreasing due to sedimentation.

When the downstream region of the middle part of Chongwe River dries up, one of its main tributaries; the Ngwerere Stream in the upstream region is reported to have flows during such times making it a unique tributary [10]. Furthermore, [11] [12] reported that the Ngwerere stream together with Kanakatampa Stream are socially, economically, and environmentally important stream for the big city of Lusaka where it originates. Little research has been conducted on the hydrological contribution of these streams to the Chongwe River. For this reason, this study assessed the contribution of the Ngwerere and Kanakatampa tributaries to the hydrology of Chongwe River Catchment with the main aim of getting a better understanding of their streamflow contribution in the catchment and factors that influence their flows. The objective of the study was to provide necessary future management options for the sustainable management of the Chongwe River Catchment.

\section{Methodology}

\subsection{Study Area}

The Chongwe River Catchment (shown in Figure 1) largely covers the Chongwe district of Lusaka province in Zambia. The catchment also covers the districts of Lusaka, Chibombo, Kafue, and a small fraction of the Luangwa district [10]. It is a sub-catchment of the Zambezi Catchment and covers a total area of $5150 \mathrm{~km}^{2}$. The Chongwe River has four main tributaries namely, Ngwerere, Kanakatampa, Chalimbana, and Luimba. The Ngwerere, (the stream of interest in this study) originates from the city of Lusaka and meanders through Lusaka and Chongwe for an approximate distance of $41 \mathrm{~km}$ before discharging into the upper part of Chongwe River. The other tributary of interest, the Kanakatampa Stream, meanders from the Kanakatampa area for approximately $52 \mathrm{~km}$ before discharging into the middle of the upper part of the Chongwe River.

The climate of Chongwe River Catchment can be described as humid subtropical with dry winters and hot summers, corresponding to class Cwa accord- 
ing to the Koppen-Geiger Classification, while weather conditions are accurately described as tropical continental highland climate [14]. The Zambian Meteorological Department (ZMD), indicate that the mean annual rainfall of Chongwe varies between $750 \mathrm{~mm}$ and $930 \mathrm{~mm}$, the mean annual temperature is approximately $20.7^{\circ} \mathrm{C}$ with the coldest months being June and July with an average temperature of $16^{\circ} \mathrm{C}$ while the maximum monthly temperatures occur in October with a mean temperature of $24^{\circ} \mathrm{C}$ [14].

In terms of economic activities, commercial agriculture is predominant in the upper part of the Chongwe Catchment while wildlife tourism is practiced in the lower eastern part of the catchment in the Lower Zambezi National Park [10] [15]. According to Nick [16], small-scale farming is also commonly practiced in Chongwe covering an area of approximately $300 \mathrm{~km}^{2}$ of the agricultural land. The agricultural activities are predominant along the Ngwerere Stream [10]. These farm areas mainly supply the city of Lusaka with fresh vegetables.

\subsection{Data Sets and Methods}

In this study, the WEAP model was used to simulate streamflow time series of the Ngwerere Stream, Kanakatampa and Chongwe River under the study scenario (1970 to 2019). Flow duration curves (FDC) were generated at two (3) locations namely, Ngwerere Confluence (NC), Kanakatampa N4 and Chongwe River Confluences (CC). Discharge at a $50 \%$ probability of exceedance $\left(\mathrm{Q}_{50}\right)$ was obtained from the FDCs in 10-year intervals of 1970-1979, 1980-1989, 1990-1999, 2000-2009, and 2010-2019.

\subsubsection{WEAP Model Data Inputs}

The Water Evaluation and Planning (WEAP) tool, developed and supported by the Stockholm Environment Institute (SEI), is a microcomputer tool for integrated water resource planning. It provides a comprehensive, flexible, and user-friendly framework for water and environment policy analysis. The WEAP model is used to imitate the hydrological relations amongst the soils, atmosphere, and runoff of a river catchment. Data inputs required by WEAP to perform these functions include Climatic data, Land use data, soil-related parameters, wastewater (WW) discharge from wastewater treatment plants (WWTPs) and river abstraction data. The climatic data were precipitation, air temperature, average air relative humidity (RH), wind speed, and cloudiness fraction. These were obtained from ZMD and SASSCAL WeatherNet stations (Figure 1) for a period from 1970 to 2019 and whose averaged monthly values are shown in Tables 1-3, show the WW discharge and surface water abstraction data used as input in WEAP respectively.

The Land use data used in this study were collected from the European Space Agency Climate Change Initiative Land Cover (ESA-CCI-LC). Under this data source, Land use is divided into seven categories. Figure 2 shows the Land use in the base year 1970 used in the WEAP. Land use and Soil related parameters associated with the Chongwe River Catchment were selected as calibration parameters. 
Table 1. Averaged monthly climate values of Chongwe River catchment (1970 to 2019).

\begin{tabular}{|c|c|c|c|c|c|c|c|c|c|c|c|c|}
\hline \multirow{2}{*}{ Climatic data } & \multicolumn{12}{|c|}{ Month } \\
\hline & Oct & Nov & Dec & Jan & Feb & Mar & Apr & May & Jun & Jul & Aug & Sep \\
\hline Average & & & & & & & & & & & & \\
\hline $\begin{array}{l}\text { Precipitation } \\
\quad(\mathrm{mm})\end{array}$ & 18.0 & 98.0 & 212.0 & 232.0 & 201.0 & 93.0 & 28.0 & 5.0 & 0.0 & 0.0 & 0.0 & 2.0 \\
\hline $\begin{array}{c}\text { Average Air } \\
\text { Temperature } \\
\left({ }^{\circ} \mathrm{C}\right)\end{array}$ & 17.8 & 17.7 & 16.6 & 14.6 & 11.4 & 8.7 & 8.2 & 10.3 & 14.1 & 17.4 & 18.2 & 18.0 \\
\hline $\begin{array}{l}\text { Average } \\
\text { RH (\%) }\end{array}$ & 39.3 & 52.4 & 73.4 & 83.7 & 85.7 & 82.5 & 80.1 & 69.2 & 63.9 & 58.1 & 48.1 & 39.8 \\
\hline $\begin{array}{c}\text { Average Wind } \\
\text { Speed }(\mathrm{m} / \mathrm{s})\end{array}$ & 39.3 & 52.4 & 73.4 & 83.7 & 85.7 & 82.5 & 80.1 & 69.2 & 63.9 & 58.1 & 48.1 & 39.8 \\
\hline $\begin{array}{c}\text { Cloudiness } \\
\text { Fraction }\end{array}$ & 0.5 & 0.3 & 0.1 & 0.1 & 0.1 & 0.3 & 0.4 & 0.7 & 0.9 & 1.0 & 1.0 & 0.7 \\
\hline
\end{tabular}

Table 2. Wastewater discharge from the LWSC treatment plants into Ngwerere stream (2011-2017) [11].

\begin{tabular}{cccccc}
\hline \multirow{2}{*}{ Month } & \multicolumn{5}{c}{ Mean Discharge Flow $\left(\mathrm{m}^{3} / \mathrm{s}\right)$ at Each Treatment Plant } \\
\cline { 2 - 5 } & Machinchi & Ngwerere Ponds & Chelstone Ponds & Kaunda Square Ponds & Total \\
\hline Jan & 0.9469 & 0.1576 & 0.0185 & 0.0247 & 1.1477 \\
Feb & 0.8777 & 0.2075 & 0.0191 & 0.0255 & 1.1298 \\
Mar & 0.8625 & 0.1296 & 0.0133 & 0.0177 & 1.0231 \\
Apr & 0.8106 & 0.1545 & 0.0123 & 0.0164 & 0.9938 \\
May & 0.8130 & 0.0957 & 0.0093 & 0.0125 & 0.9305 \\
Jun & 0.7416 & 0.0809 & 0.0123 & 0.0164 & 0.8512 \\
Jul & 0.6783 & 0.2411 & 0.0078 & 0.0103 & 0.9375 \\
Aug & 0.7082 & 0.0984 & 0.0088 & 0.0117 & 0.8271 \\
Sep & 0.7191 & 0.1035 & 0.0082 & 0.0110 & 0.8418 \\
Oct & 0.6299 & 0.0816 & 0.0065 & 0.0086 & 0.7266 \\
Nov & 0.7699 & 0.0835 & 0.0071 & 0.0095 & 0.8700 \\
Dec & 0.7987 & 0.3045 & 0.0240 & 0.0320 & 1.1592 \\
Mean flow & 0.7797 & 0.1449 & 0.0123 & & 0.9533 \\
(m $\left.{ }^{3} / \mathrm{s}\right)$ & & & & & \\
\hline
\end{tabular}

Table 3. Surface water abstractions in Chongwe river catchment for the years 1983-2017 [11].

\begin{tabular}{cccccc}
\hline Year & $\begin{array}{c}\text { Water } \\
\text { Supply } \\
\left(\mathrm{Mm}^{3}\right)\end{array}$ & $\begin{array}{c}\text { Irrigation } \\
\left(\mathrm{Mm}^{3}\right)\end{array}$ & $\begin{array}{c}\text { Livestock } \\
\text { Water } \\
\text { use }\left(\mathrm{Mm}^{3}\right)\end{array}$ & $\begin{array}{c}\text { Eco System } \\
\text { Maintenance } \\
\left(\mathrm{Mm}^{3}\right)\end{array}$ & $\begin{array}{c}\text { Total Surface } \\
\text { water Abstraction } \\
\left(\mathrm{Mm}^{3}\right)\end{array}$ \\
\hline $2016 / 2017$ & 1.14 & 57.02 & 2.01 & 30.02 & 90.19 \\
$2014 / 2015$ & 1.03 & 52.56 & 1.94 & 28.54 & 84.07 \\
$2003 / 2004$ & 0.95 & 34.82 & 1.76 & 21.21 & 58.74 \\
$1993 / 1994$ & 0.92 & 19.29 & 1.32 & 19.51 & 41.04 \\
$1983 / 1984$ & 0.63 & 13.77 & 1.52 & 18.94 & 34.86 \\
\hline
\end{tabular}




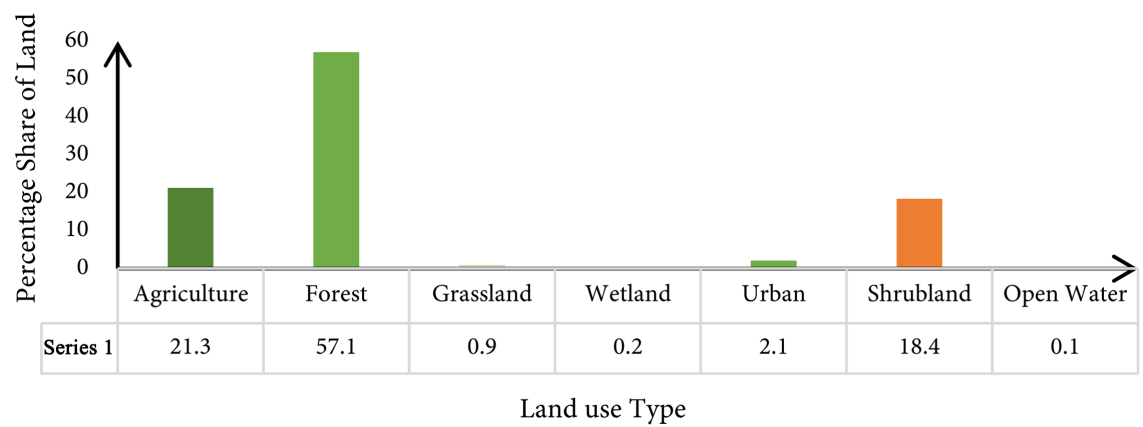

Figure 2. Land use categories and percentage shares (Series 1) for the base year 1970 used in WEAP.

\subsubsection{WEAP Model Calibration}

The WEAP model was calibrated and validated using the PEST auto-calibration tool available within the WEAP tool. Five calibration parameters were selected to determine the upper bounds, lower bounds and optimal values which were obtained after the successful running of the PEST tool according to the framework shown in Figure 3. Table 4 shows the upper bound, lower bound and optimum value for each parameter. Measured Streamflow data (1970-2010) at the Chongwe Great East Road Bridge gauging station (5-025) collected from WARMA were selected for the calibration process. The Calibration period was from 1970 to 1999 while the Validation period was from 2000 to 2010 . The model calibration performance was assessed using the correlation coefficient (CC), Coefficient of determination $\left(R^{2}\right)$, Nash-Sutcliffe Coefficient of Efficiency (NSE), and Percent bias (PBIAS). The goodness of the WEAP model results was assessed using the recommended hydrological model performance results by [17] and shown in Table 5.

\section{Results}

\subsection{Model Calibration and Validation Results}

Figure 4 shows the variation of the observed and simulated monthly streamflow obtained after running the PEST auto-calibration in WEAP during the calibration (1970-1999) and validation (2000-2010) periods. The results of the calibration and validation in terms of hydrological model performance measures are described in Table 6.

\subsection{Flow Duration Curves (FDCs) and Streamflow Contributions}

FDCs (Figures 5(a)-(e)) were generated for 10-year periods, 1970-1979, 1980-1989, 1990-1999, 2000-2009, and 2010-2019 for the Ngwerere stream, Kanakatampa stream and Chongwe river. As shown in Table $7, \mathrm{Q}_{50}$ was obtained from the FDCs. The contributions of the Ngwerere and Kanakatampa streams were calculated and presented in Table 7 and Figure 6. The Table shows that the Ngwerere Stream and Kanakatampa streams contribute an average of $52.8 \%$ and $29.6 \%$ to the streamflow of the Chongwe River, respectively. Trend analysis 


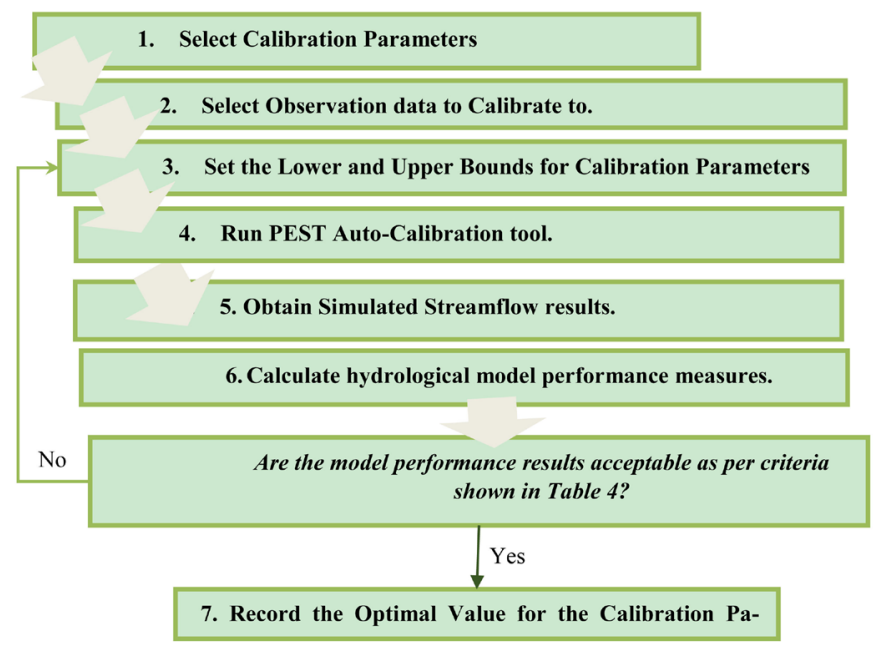

Figure 3. WEAP model calibration process framework using PEST auto-calibration program.

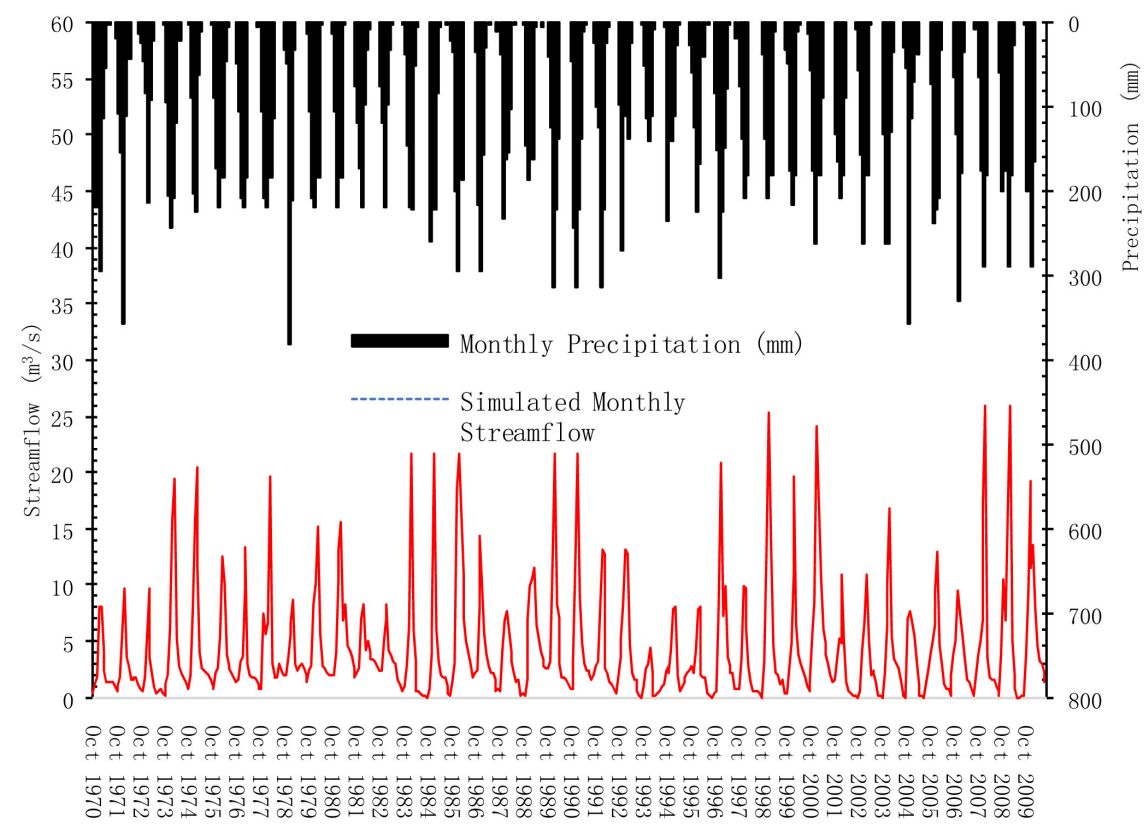

Figure 4. Observed and simulated streamflow including precipitation of the chongwe river catchment during the WEAP model calibration period (1970-2000) and validation period (2000-2010).

Table 4. WEAP Parameters and their boundaries details used in PEST calibration of the model.

\begin{tabular}{ccccc}
\hline Parameter & Units & Lower bound & Upper bound & Optimal Value \\
\hline Root Zone Conductivity & $\mathrm{mm} / \mathrm{month}$ & 0 & 999 & 119.88 \\
Preferred flow direction & dimensionless & 0 & 1 & 0.05 \\
Runoff resistance factor & dimensionless & 0 & 500 & 200 \\
Crop Coefficient (Forest) & dimensionless & 0.5 & 2 & 2 \\
Deepwater conductivity & $\mathrm{mm}$ & 100 & 2000 & 2000 \\
\hline
\end{tabular}




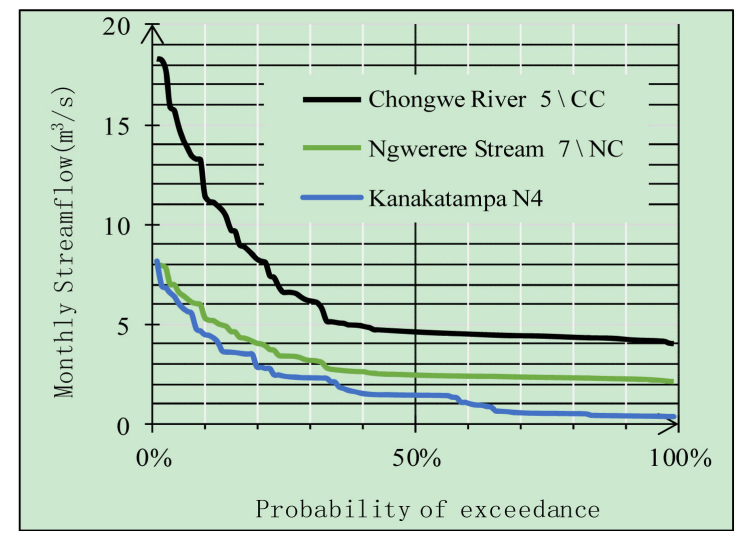

(a)

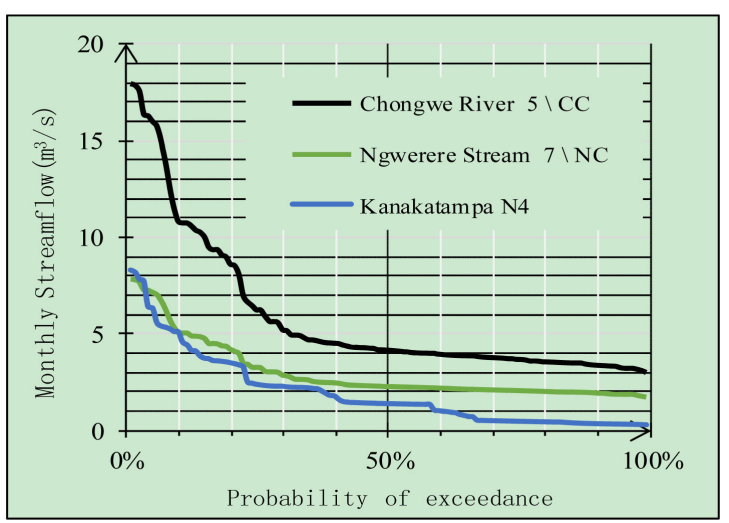

(b)

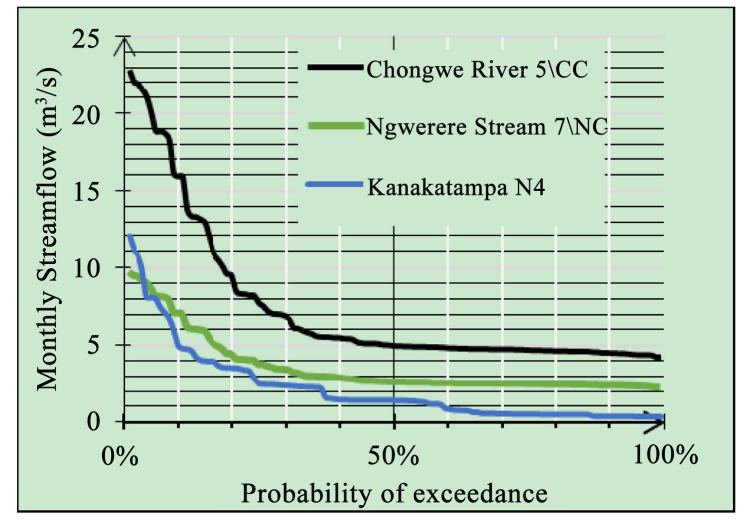

(c)

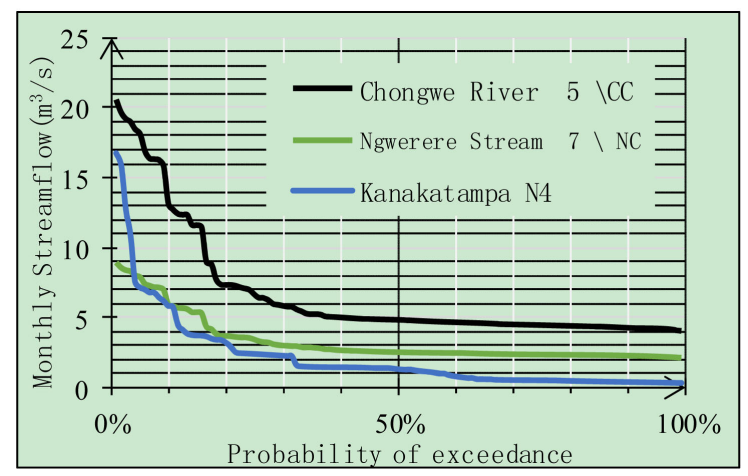

(d) 


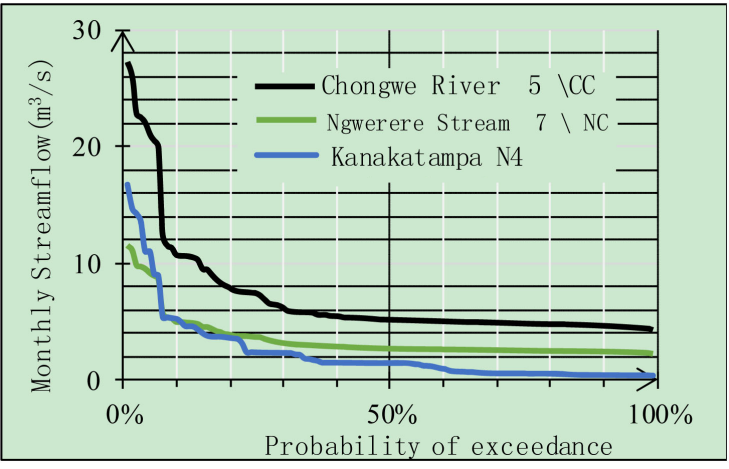

(e)

Figure 5. WEAP generated FDCs at station NC (Ngwerere stream), N4 (Kanakatampa Stream) and CC (Chongwe river) (a) 1970-1979; (b) 1980-1989; (c) 1990-1999; (d) 2000-2009; (e) 2010-2019.

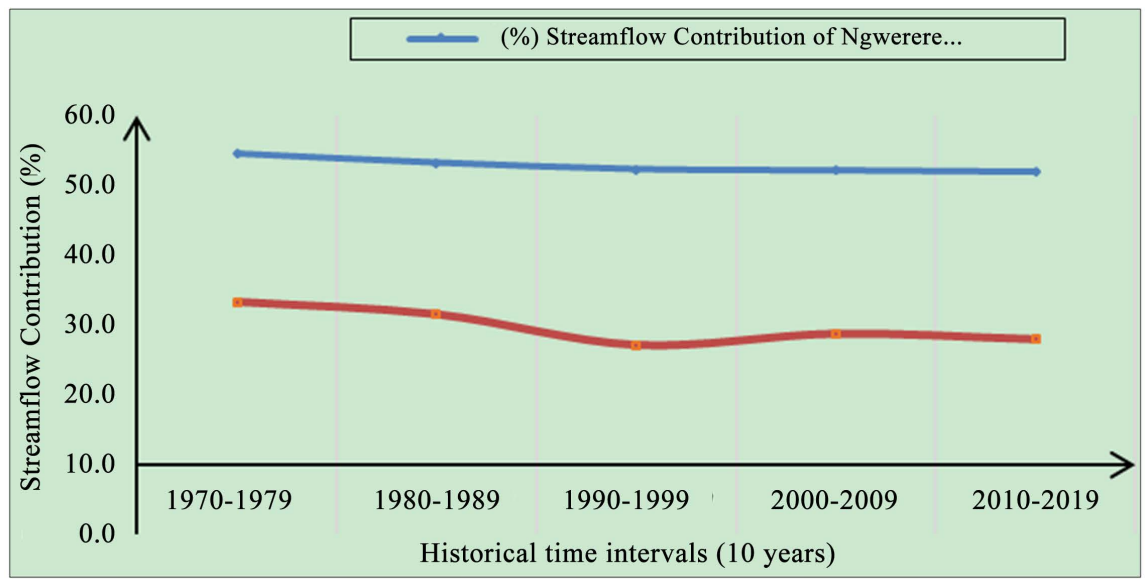

Figure 6. Historical variation of the contribution (c) of Ngwerere stream to flows of Chongwe River.

Table 5. Classification criteria for hydrological models [17].

\begin{tabular}{cccc}
\hline Goodness-of-Fit & NSE & PBIAS (\%) & R2 \\
\hline Very Good (V) & $0.75<$ NSE $\leq 1.00$ & PBIAS $< \pm 10$ & R2 $\geq 0.75$ \\
Good (G) & $0.60<$ NSE $\leq 0.75$ & $\pm 10 \leq$ PBIAS $< \pm 15$ & $0.70<$ R2 $\leq 0.75$ \\
Satisfactory (S) & $0.50<$ NSE $\leq 0.60$ & $\pm 15 \leq$ PBIAS $< \pm 45$ & $0.60<$ R2 $\leq 0.75$ \\
Unsatisfactory (U) & NSE $\leq 0.50$ & PBIAS $\geq \pm 45$ & R2 $<0.60$
\end{tabular}

Table 6. Hydrological model performance measures achieved during the calibration period (1970-2010).

\begin{tabular}{ccc}
\hline \multirow{2}{*}{ Performance measure } & \multicolumn{2}{c}{ Performance achieved } \\
\cline { 2 - 3 } & Calibration Period & Validation \\
\hline CC & 0.81 & 0.81 \\
R2 & 0.66 & 0.67 \\
NSE & 0.62 & 0.62 \\
PBIAS & $1.24 \%$ & 2.94 \\
\hline
\end{tabular}


Table 7. The historical contribution of Ngwerere stream to the streamflow of the Chongwe River.

\begin{tabular}{cccccc}
\hline \multirow{2}{*}{$\begin{array}{c}\text { 10-year } \\
\text { Interval }\end{array}$} & $\begin{array}{c}\mathrm{Q}_{50}\left(\mathrm{~m}^{3} / \mathrm{s}\right) \\
\text { Chongwe } \\
\text { River/CC }\end{array}$ & $\begin{array}{c}\text { Ngwerere } \\
\text { Stream/NC }\end{array}$ & $\begin{array}{c}\text { Kanakatampa } \\
\mathrm{N} 4\end{array}$ & $\begin{array}{c}\text { Ngwerere } \\
\text { Stream/NC }\end{array}$ & $\begin{array}{c}\text { Kanakatampa } \\
\text { N4 }\end{array}$ \\
\hline $1970-1979$ & 4.147 & 2.262 & 1.377 & 54.545 & 33.205 \\
$1980-1989$ & 4.609 & 2.453 & 1.449 & 53.236 & 31.438 \\
$1990-1999$ & 4.847 & 2.534 & 1.312 & 52.282 & 27.068 \\
$2000-2009$ & 4.980 & 2.594 & 1.427 & 52.095 & 27.655 \\
$2010-2019$ & 5.140 & 2.666 & 1.433 & 51.874 & 27.879 \\
Average (\%) & & & 52.806 & 29.649 \\
\hline
\end{tabular}

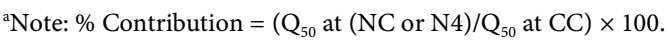

was also performed using the Mann Kendal non-parametric test to determine the significant of the trends in the time series as well calculating the slopes. The results of the Mann Kendal test are shown in Table 8.

\section{Discussion}

\subsection{WEAP Model Calibration and Validation Results}

Assessing the calibration and validation model results in terms of performance measures shown in Table 5, WEAP generally overestimated the simulated streamflow as indicated by a positive PBIAS of $1.24 \%, \mathrm{CC}=0.81, \mathrm{R}^{2}=0.66$ and NSE $=0.62$ during the calibration period and a positive PBIAS of $2.94 \%, \mathrm{CC}=$ $0.81, \mathrm{R} 2=0.67$ and NSE $=0.62$ during the validation period. The overestimation could be attributed to the presence of 46 missing data in the monthly precipitation and 49 missing data in the observed monthly streamflow data during the calibration period (1970-2010). The missing data were interpolated using WEAP during the data input process. Interpolation could be one of the sources of overestimation. Furthermore, the overestimation could be due to the PEST auto-calibration software embedded in WEAP since it uses a single objective function in the calibration process. Bao et al. [18] suggested the usage of other software that use multi-objective functions such as genetic algorithm II (NSGA-II) to improve future streamflow results. This algorithm is currently not available in the WEAP embedded PEST auto-calibration software.

\subsection{Contributions of the Ngwerere and Kanakatampa Streams to the Flows of Chongwe River}

As shown in Table 4, the Ngwerere Stream contributed 54.5\%, 53.2\%, 52.3\%, $52.1 \%$, and $51.1 \%$ in the consecutive 10 -year periods of 1970-1979, 1980-1989, 1990-1999, 2000-2009 and 2010-2019, respectively. The average contribution over these 50 years was found to be $52.8 \%$. Therefore, in general terms, the Ngwerere Stream provides more than half of the Chongwe River flows into the upper and middle parts of the Chongwe Catchment. According to [10] and 
Table 8. Mann-Kendall trend test/two-tailed test (\% Contribution).

\begin{tabular}{ccc}
\hline Parameters & Ngwerere & Kanakatampa \\
\hline S & -10.000 & -4.000 \\
$\mathrm{Z}$ & -2.205 & -0.735 \\
p-value (Two-tailed) $^{\mathrm{b}}$ & 0.028 & $<0.0001$ \\
alpha & 0.050 & 0.050 \\
Sen's Slope & -0.648 & -1.345 \\
Y-Intercept & 54.751 & 33.679 \\
\hline
\end{tabular}

b. An approximation has been used to compute the p-value.

visual inspection, there is a small continuous flow of the Chongwe River in the upper and middle regions of the Catchment in dry seasons and this is due to the continuous flow of wastewater discharged into the Ngwerere Stream from the seven (7) wastewater treatment plants (WWTPs) in the city of Lusaka. This could explain the reason as to why the Chongwe River does not dry up in these regions during the dry seasons until the water is impounded by downstream commercial and small-scale farmers in the upper and middle part of Chongwe River Catchment. The Kanakatampa stream is also of significant importance to the flows of Chongwe river as it contributes an estimated 30\% to the flows of the River in the middle part of the catchment.

Trend analysis of the historical contribution of both the Ngwerere and the Kanakatampa streams to the flows of the Chongwe River (Figure 6) showed that the contribution of the two streams had been reducing at an average rate of $0.65 \%$ and $1.35 \%$ per 10 -year period respectively. The Mann Kendal test performed on during the trend analysis showed that these decreasing trends were significant as the calculated $\mathrm{p}$-values were less than alpha (0.050). The significant decreasing rates could be attributed to the following factors:

1) The increase in irrigated area around Ngwerere Stream: Tena et al. [12] showed that the irrigated area in Chongwe Catchment is increasing at a rate of $1.70 \mathrm{~km}^{2} /$ annum. Therefore, more water is continuously being withdrawn by the farmers along the Ngwerere stream, thereby reducing the flows into the Chongwe River.

2) Reduced efficiency of WWTWs in Lusaka: According to [19], the two conventional WWTWs in Lusaka were in poor conditions and were no longer operating at their optimum design discharge. Furthermore, the remaining five non-conventional stabilization ponds were not being disludged since the time of their construction thereby resulting in excess sludge accumulation which consequently reduced their volumetric capacity and efficiency [19]. These factors subsequently resulted in the reduction of treated wastewater discharged into the Ngwerere Stream.

3) Decreasing rainfall trend: The historical rainfall trend line of Chongwe catchment shows a decreasing rate. This decreasing rate has also been reported by [10] and [12]. Streamflow responds largely to rainfall patterns both in terms 
of runoff and baseflow. The reduction in rainfall could be attributed to the significant increase in urban land at the expense of forest land. Charcoal burning which is very common in the rural areas of Chongwe could also be the reason.

4) The decrease in baseflow: The increase in urbanization or built-up area increases the runoff coefficients which reduces baseflow and subsequently increases runoff. While the runoff results in high flows during rainy times, baseflow remains the main source of the continuous flow of streams both in wet and dry seasons [20]. Tena et al. [12] reported that the built-up area in Chongwe has been increasing at a rate of $6.97 \mathrm{~km}^{2}$ per annum. Therefore, baseflow and consequently streamflow contribution of the Ngwerere stream is expected to continue decreasing with the ever-growing urbanization in the cities of Chongwe and Lusaka.

\section{Conclusions and Management Options}

\subsection{Conclusions}

This study presented a simplified process of assessing the streamflow contribution of the Ngwerere Stream to the streamflow of the Chongwe River as part of the hydrological study of the water-stressed Chongwe River Catchment in Zambia. The study revealed that the Ngwerere streamflow generally contributes more than half of the flows of the Chongwe River considering the median flows $\left(\mathrm{Q}_{50}\right)$ obtained from the FDCs over the 50 years. The study also revealed that the contribution of the Ngwerere Stream to the flows of the Chongwe River has been historically reducing at a rate of $0.648 \%$ per 10 year period and this is expected to continue reducing with the ever-growing urbanization in the cities of Lusaka and Chongwe. The results of this study were found to be in line with the findings of other studies conducted in the Chongwe River Catchment by authors in [10] [11] [12] [19].

WEAP model was used in this study to simulate the historical streamflow of the Ngwerere and Kanakatampa Streams just before the confluences with the Chongwe River as well as flows of the Chongwe main River. The results of WEAP in terms of calibration and validation performance measures showed a PBIAS of $1.24 \%, \mathrm{CC}=0.81, \mathrm{R} 2=0.66$ and NSE $=0.62$ during the calibration period and a positive PBIAS of $2.94 \%, \mathrm{CC}=0.81, \mathrm{R} 2=0.67$ and $\mathrm{NSE}=0.62$ during the validation period. These results indicate that WEAP is a good tool that can be used for the hydrological modelling of our study area and other similar river catchments in Zambia and other parts of the globe.

\subsection{Management Options}

The rainfall and observed streamflow data used in the study had missing data that were interpolated by WEAP. This could have been the reason for the general overestimation of the simulated streamflow by the WEAP model. It is suggested that in future studies, a detailed missing data interpolation process should be conducted before the WEAP data inputting process to improve the accuracy 
of the results. In the same line, it is suggested that other sources of accurate climatic data in the Chongwe River Catchment should be investigated.

The results of this study show that the significant contribution of the Ngwerere Stream to the flows of the Chongwe River has been reducing historically. This calls for catchment management practices that will maintain and improve the significant contribution of the Ngwerere stream to the flows of Chongwe River and subsequently reduce the chances of the Chongwe River from experiencing little or no flows in the downstream. Based on some of the reasons identified in this study, as causes of the reduction in the Ngwerere Streamflow, the recommended practices may include: 1) regulated withdraw of water from the Ngwerere Stream by the increasing numbers of farmers, 2) cleaning and maintaining the wastewater treatment plants in the city of Lusaka to increase their capacity and subsequently the discharge to the Ngwerere Stream, and 3) implementing appropriate catchment management options and protection of the source of the tributary streams which can increase baseflow. Management recommendations made by the authors in [10] [11] [12] [19] should also be put in place. Furthermore, poor catchment management of the upper part of the Chongwe River Catchment is the main contributor to the land and water degradation, poor water use efficiency, and productivity. It is also important to regularly monitor the water quality of effluents before discharging into the stream based on the environmental management standards. Catchment water resources protection and management are some of the key solutions to conserve natural resources and to attain sustainable socio-economic development in the catchment. An appropriate catchment protection measures such as plantation and conservation of vegetation, constructing recharge ponds, and protection of the recharge area can play an important role in improving the interactions between surface water and groundwater system. The catchment protection and management measures should focus on the tributaries of Chongwe River, such as Ngwerere and Kanakatampa Stream.

\section{Conflicts of Interest}

The authors declare no conflicts of interest regarding the publication of this paper.

\section{References}

[1] JICA (2003) The National Water Resources Master Plan. Yachiyo Engineering Co. Ltd. (YEC), Lusaka.

[2] Mohamed, A., Gitaw, M.W. and Engel, B.A. (2019) Hydrological Response in an Urban Watershed as Affected by Climate and Land Use Change. MDPI Water, 29.

[3] Gleick, P.H., Cooley, H., Famiglietti, J., Lettenmaier, D., Oki, T., Wood, E., Vorosmarty, C. and Wood, E. (2011) Improving Understanding of the Global Hydrological Cycle. Conference World Climate Research Programme (WCRP), Denver, 24-28 October 2011, 151-184.

[4] Smith, J.P. and Gronewold, A.D. (2017) Development and Analysis of a Bayesian 
Water Balance Model for Large Lake Systems.

[5] Toda, O., et al. (2004) Evaluation of Tributaries Contribution in the Mekong River Basin during Rainy and Dry Seasons. Proceedings of the 2 nd Conference of the Asia Pacific Association of Hydrology and Water Resources, Singapore, 2-7 August 2015, 239-248.

[6] Brueggen, T.R., Bowling, C.B. and Bouldin, J.L. (2010) Tributary Contribution to the Spring River, AR as Determined by Water Quality Analyses. Journal of the Arkansas Academy of Science, 64, 70-76.

[7] Bren, L.J. (1991) The Contribution of River Murray Tributaries to the Flooding of Barmah Forest. Taylor and Francis, 54, 23-29. https://doi.org/10.1080/00049158.1991.10674553

[8] UN-ESCWA and BGR (2013) Inventory of Shared Water Resources in Western Asia. Beirut.

[9] WARMA (2018) Annual Report 2017. Water Resources Management Authority (WARMA), Lusaka.

[10] Chisola, M.N. and Kuráž, M. (2016) Patterns and Implications of Hydrologic Regime Change in Chongwe River, Zambia. Journal of Geography, 8, 1-2. https://doi.org/10.5539/jgg.v8n3p1

[11] Tena, T.M., Mwaanga, P. and Nguvulu, A. (2019) Hydrological Modelling and Water Resources Assessment of Chongwe River Catchment Using WEAP Model. MDPI Water, 1-17. https://doi.org/10.37247/WEM.1.2019.1-31

[12] Tena, T.M., Mwaanga, P. and Nguvulu, A. (2019) Impact of Land Use/Land Cover Change on Hydrological Components in Chongwe River Catchment. Sustainability, 12, 6415. https://doi.org/10.3390/su11226415

[13] Chomba, C.L. and Sichingabula, M.H. (2015) Sedimentation and Its Effects on Selected Small Dams East of Lusaka, Zambia. Modern Environmental Science and Engineering, 1, 325-340. https://doi.org/10.15341/mese(2333-2581)/06.01.2015/007

[14] Mbale, B.S., Siwale, C., Baumie, R. and Krekeler, T. (2012) Water Balance Estimates for Sub-Catchments of the Chongwe and Mwembeshi Rivers in the Lusaka Region. Ministry of Mines, Energy and Water Development, Lusaka.

[15] Jenkins, M., Nick, A., Mwelwa, D. and Simwana, T. (2015) Groundwater Resources for Lusaka and Selected Catchment Areas-Technical Report No. 1-Impact of Small Scale Farming on the Chongwe River on Land Use and Water Abstractions from Chongwe River. Water Resources Management Authority, Lusaka.

[16] Nick, A. (2015) The Chongwe Catchment: A Hydrological, Hydrogeological and Hydrochemical Characterisation for the Establishment of a Catchment Management Plan. MEWD, Lusaka.

[17] Moriasi, D.N., Gitau, M.W., Daggupati, P. and Pai, N. (2015) Hydrologic and Water Quality Models: Performance Measures and Evaluation Criteria. American Society of Agricultural and Biological Engineers (ASABE), St. Joseph, 1763-1785. https://doi.org/10.13031/trans.58.10715

[18] Pham, B.Q., et al. (2017) Assessment of Climate Change Impacts on Hydrological Processes and Water Resources by Water Evaluation and Planning (WEAP) Model: Case Study in Thac Mo Catchment, Vietnam. Proceedings of the 37 th IAHR World Congress, Kuala Lumpur, 13-18 August 2017, 4312-4321.

[19] Wamukwamba, C.K. and Share, K. (2001) Sewage Waste Management in the City of Lusaka. WEDC Conference, Lusaka, 20-24 August 2001, 211-212.

[20] Subramanya, K. (2008) Engineering Hydrology. 3rd Edition, Tata McGraw-Hill Companies Limited, New Delhi. 